\title{
OPEM
}

www.opem.org

Oriental Pharmacy and Experimental Medicine 2008 8(2), 171-177

DOI 10.3742/OPEM.2008.8.2.171

\section{In vitro and in vivo antidiarrhoeal activity of epigallocatechin 3-gallate: a major catechin isolated from indian green tea}

\author{
Durba Bandyopadhyay ${ }^{1}$, Pradeep Kumar Dutta ${ }^{2}$, Sujata G Dastidar ${ }^{1}$ and Tapan Kumar Chatterjee ${ }^{1, *}$ \\ ${ }^{1}$ Department of Pharmaceutical Technology, Jadavpur University, Kolkata 700 032, India; ${ }^{2}$ Indian Institute of \\ Chemical Biology; 4, Raja S. C. Mallik Road, Kolkata 700 032, India
}

Received for publication May 09, 2007; accepted October 16, 2007

\begin{abstract}
SUMMARY
Epigallocatechin 3-gallate (EGCG), one of the major catechins of tea, was isolated from the decaffeinated, crude methanolic extract of Indian green tea (Camellia sinensis L. O. Kuntze) using chromatographic techniques. EGCG was then screened for antidiarrhoeal activity against 30 strains (clinical isolates) of $V$. cholerae, which is a well known Gram negative bacillus functioning as the pathogen of cholera. $V$. cholerae strains like $V$. cholerae $69,71,83,214,978$, $1021,1315,1347,1348,569 \mathrm{~B}$ and ATCC 14033 were inhibited by EGCG at a concentration of 25 $\mu \mathrm{g} / \mathrm{ml}$ whereas $V$. cholerae $10,522,976$ were even more sensitive, being inhibited at $10 \mu \mathrm{g} / \mathrm{ml}$ level. However, V. cholerae DN 16, DN 26, 30, 42, 56, 58, 113, 117, 564, 593, 972 and ATCC 14035 were inhibited at $50 \mu \mathrm{g} / \mathrm{ml}$ level of EGCG. Only four strains were inhibited at $100 \mu \mathrm{g} / \mathrm{ml}$. In this study the isolated compound was found to be bacteriostatic in its mechanism of action. In the in vivo experiment using the rabbit ileal loop model two different dosages of EGCG ( $500 \mu \mathrm{g} /$ $\mathrm{ml}$ and $1,000 \mu \mathrm{g} / \mathrm{ml}$ ) were able to protect the animals when they were challenged with $V$. cholerae 569B in the ileum.
\end{abstract}

Key words: Antidiarrhoeal activity; Rabbit ileal loop; Camellia sinensis (L.) O. Kuntze; Epigallocatechin 3-gallate

\section{INTRODUCTION}

Over the last 50 years a number of known antibiotics have proved to be ineffective due to accelerated drug resistance. Hence the scientists are combing the earth for botanicals / phytochemicals which could be substantially proved as antimicrobial agents. Camellia sinensis (L.) O. Kuntze, belonging to the family Theaceae, has long been used as a traditional healer of a number of disorders. In

*Correspondence: Department of Pharmaceutical Technology, Jadavpur University, Kolkata 700 032, West Bengal, India. Tel: +913324079782; Fax: +913324079782; E-mail: tkchatterjee81@yahoo.co.in recent years tea has been recommended for various types of activities, eg. antioxidant potentiality (Nagamori and Okay, 2001), anticancer property (Hirose et al., 1994; Gupta et al., 1999), hepatoprotective activity (Hasegawa et al., 1995) and also antiatherogenic property (Muramatsu et al., 1986; Yang and Koo, 1997, 2000). In the present study, epigallocatechin 3-gallate, one of the potential active ingredients (Graham, 1992; Balentine et al., 1997; Amarowicz and Shahidi, 2003) of green tea, was isolated from decaffeinated crude extract of green tea through column chromatography (Bettolo $e t$ al., 1981) using Diaion HP 20 and silica gel (60 - 120 mesh size) followed by preparative thin layer 
chromatography. Some pharmacological activities (Suzuki et al., 1998; Wang et al., 2001) of green tea catechins have already been established. In this work an attempt has been made to evaluate the antibacterial activity of epigallocatechin 3-gallate (EGCG) against virulent strains of $V$. cholerae.

\section{MATERIALS AND METHODS}

\section{Method of extract preparation}

Methanolic extract was prepared using mature leaves of Camellia sinensis (Indian green tea) which were collected, washed with distilled water and allowed to dry at $37^{\circ} \mathrm{C}$. These were then pulverized to form a coarse powder. The powdered leaves were decaffeinated with the help of carbon dioxide $\left(\mathrm{CO}_{2}\right)$ (Peker et al., 1992; Saldana et al., 2000). After decaffeination, the tea leaf powder was soaked in petroleum ether overnight at room temperature in order to get rid of the sticky gummy substances from the material. This was then dried at $60^{\circ} \mathrm{C}$. This dry powder of Camellia sinensis (L.) was extracted in a Soxhlet apparatus with methanol. The solvent was removed under reduced pressure in a rotary evaporator at $40^{\circ} \mathrm{C}$. A dry light brown powder was obtained. The powdered extract was found to be water-soluble. This dry, powdered extract was subjected to column chromatography using Diaion HP 20 and silica gel (60 - 120 mesh size) followed by preparative thin layer chromatography when EGCG could be isolated. This was then characterized by the Mass NMR spectral analyses of the compound. ESI - mass spectrum was recorded in a Waters ' $Q$ TOF - MICRO' instrument and NMR spectrum was recorded in BRUKER $600 \mathrm{MHZ}$ spectrometer.

\section{Bacteria}

A total of 30 strains of $V$. cholerae were tested in vitro of which 28 were of human origin, identified as described by Barrow and Feltham (1993) and two ATCC strains (14033 \& 14035) were procured from American Type Culture Collection. All strains were preserved in freeze-dried state.

\section{Media}

Liquid media used for this study were peptone water (PW, Oxoid brand bacteriological peptone $1 \%(\mathrm{w} / \mathrm{v}$ ) plus Analar $\mathrm{NaCl}$ 0.5\% (w/v), and $\mathrm{Mc}$ Conky broth (Oxoid). Solid media were: Mc Conky agar (MCA), obtained by solidifying the liquid media with $1.2 \%(\mathrm{w} / \mathrm{v})$ agar (Oxoid No. 3) and bromothymol blue lactose agar (BLA) in which bromothymol blue indicator $1.2 \%(\mathrm{w} / \mathrm{v})$ and lactose $1 \%(\mathrm{w} / \mathrm{v})$ were added to nutrient agar (Oxoid) base. The $\mathrm{pH}$ was maintained at 7.5 - 7.6 in all the media.

\section{In vitro screening of EGCG for detection of antidiarrhoeal activity}

The MIC (minimum inhibitory concentration) of the EGCG with respect to different $V$. cholerae strains was accurately determined by agar dilution methods. For this purpose the compound was dissolved in sterile distilled water and added at concentrations of 0 (control), 5, 10, 25, 50, 100 and $200 \mu \mathrm{g} / \mathrm{ml}$ to molten Mc Conky agar medium and poured in Petridishes according to NCCLS (National Committee for Clinical Laboratory Standards, 1993). The organisms were grown in PW, and the overnight culture was spot-inoculated on the MCA plates such that each inoculum contained $2 \times 10^{6}$ $\mathrm{CFU}$. The plates were incubated at $37^{\circ} \mathrm{C}$, examined after $24 \mathrm{~h}$ and incubated further for $72 \mathrm{~h}$, where necessary. The lowest concentration of the compound in a plate that inhibited any visible macroscopic growth was considered as its MIC. The MIC determination was performed in duplicate for each organism, and the experiment was repeated where necessary.

\section{Mechanism of action of EGCG}

$V$. cholerae strain 569B sensitive to EGCG was taken and grown in $4 \mathrm{ml}$ of Mc Conky broth for $18 \mathrm{~h}$. Then, $2 \mathrm{ml}$ of this culture was added to $4 \mathrm{ml}$ of fresh Mc Conky broth and incubated at $37^{\circ} \mathrm{C}$ for $2 \mathrm{~h}$ to help the strain attain logarithmic growth phase. At this stage, the CFU count was determined and 
EGCG was added at a concentration higher than the MIC. The CFU counts from the culture were individually taken after 2, 4, 6 and $18 \mathrm{~h}$ of addition of the drug.

\section{In vivo tests}

Healthy male New Zealand white rabbits; each weighing $2 \mathrm{~kg}$ were used for the in vivo study (De and Chatterjee, 1953). Animals were maintained at standard conditions at $21 \pm 1^{\circ} \mathrm{C}$ and $50-60 \%$ relative humidity with a photoperiod of $14: 10 \mathrm{~h}$ of light and darkness. The experimental rabbit was subjected to fasting for $24 \mathrm{~h}$ prior to surgery but water was provided ad libitum. Laparotomy was performed to externalize the intestine by aseptic technique under anaesthesia by using anaesthetic ether (E. Merck). Loops were created in the ileum (Gorbach et al., 1970; Hara et al., 1997; Chakraborty et al., 2000; Hiroshi et al., 2002) by placing ligatures at $3-5 \mathrm{~cm}$ intervals and separating loops with 1.5 to $2.5 \mathrm{~cm}$ interposing loops. Strain of $V$. cholerae 569B (a known rabbit virulent strain) was grown initially in solid MCA medium. From the pure culture one loopful was transferred into $5 \mathrm{ml}$ peptone water incubated for $24 \mathrm{~h}$ and the number of cells was adjusted to approximately $10^{8} \mathrm{CFU} / \mathrm{ml}$. Four loops were prepared in the externalized rabbit ileum using proper ligation. Starting with the negative control loop (containing no drug) followed by lower concentration of EGCG administered loop, higher concentration of EGCG administered loop and positive control loop (containing $10^{8} \mathrm{CFU}$ of 569B only) were prepared accordingly. Except negative control loop all other loops were administered with $0.5 \mathrm{ml}$ of $24 \mathrm{~h}$ old culture of $V$. cholerae $569 \mathrm{~B}$. Negative control loop was administered with $0.7 \mathrm{ml}$ of fresh peptone water only to make up the volume of the loop so that each loop showed the same swelling at the onset. The next loop after negative control was administered with $0.5 \mathrm{ml}$ of culture and $500 \mu \mathrm{g} / \mathrm{ml}$ of EGCG $(0.2 \mathrm{ml}$ from a stock solution of $2.5 \mathrm{mg} / \mathrm{ml}$ of EGCG). Then the third loop was given $0.5 \mathrm{ml}$ of culture of $V$. cholerae $569 \mathrm{~B}$ and $1,000 \mu \mathrm{g} / \mathrm{ml}$ of EGCG $(0.2 \mathrm{ml}$ from a stock solution of $5 \mathrm{mg} / \mathrm{ml}$ of EGCG). Fourth loop or the positive control loop was given only $0.7 \mathrm{ml}$ of $24 \mathrm{~h}$ old culture of $V$. cholerae 569B.

Finally the ligated rabbit ileum was again packed inside the body and the skin layers of the dorsal surface were sutured perfectly. The animal was taken back to the cage. After $18 \mathrm{~h}$, the rabbit was sacrificed using chloroform (E. Merck). Fluid was collected separately and aseptically from each loop of the ileum. CFU counts of individual loop were determined aseptically. The same experiment was performed on 4 more rabbits and the result of 1 rabbit is being explained. Animal experiments were conducted in accordance with the experimental animal guidelines of the institution.

\section{RESULTS}

\section{Isolation and identification of the purified compound} The isolated compound is an amorphous powder $[\alpha]^{25}-175.3\left(\mathrm{c}=0.3, \mathrm{CH}_{3} \mathrm{OH}\right)$. The ESI-MS spectrum in positive mode exhibited a peak at $m / z 481.34\left(\mathrm{M}^{+}\right.$ $+\mathrm{Na}$ ), in agreement with the sodiated molecular ion peak. This was confirmed by the highresolution mass spectrum in negative mode (Fig. $1 \mathrm{~A}$ ) of the compound, which gave a peak at $\mathrm{m} / \mathrm{z}$ 457.0759 (calculated mass for $\mathrm{C}_{22} \mathrm{H}_{17} \mathrm{O}_{11}$ : 457.771) attributed to $(\mathrm{M}-\mathrm{H})^{-}$establishing the molecular formula of the compound as $\mathrm{C}_{22} \mathrm{H}_{18} \mathrm{O}_{11}$.

The ${ }^{1} \mathrm{H}$ NMR spectrum (Fig. 1B) of the compound (600 MHz, $\mathrm{CD}_{3} \mathrm{OD}$ ) showed a pair of double doublets at $\delta 2.84 \mathrm{ppm}(J=3,17 \mathrm{~Hz})$ and at $\delta 2.96$ $\operatorname{ppm}(J=4,17 \mathrm{~Hz})$ which were assigned to $\mathrm{C}_{4}-\mathrm{H}_{\mathrm{A}}$ and $\mathrm{C}_{4}-\mathrm{H}_{\mathrm{B}}$ of the flavan moiety. A broad singlet at $\delta 4.97 \mathrm{ppm}(1 \mathrm{H})$ was typical of $\mathrm{C}_{2}-\mathrm{H}$ of epicatechins indicating the presence of the epicatechin moiety in the compound. The broad t-like $1 \mathrm{H}$ signal at $\delta 5.53$ was assigned to $C_{3}-H$. The down field shift of $C_{3}-$ proton $(\delta 5.53 \mathrm{ppm})$ in comparison to that of epigallocatechin was indicative of the location of an acyl group at this position. A two-proton singlet at $\delta 5.95 \mathrm{ppm}$ was assigned to $\mathrm{C}_{6}-\mathrm{H}$ and $\mathrm{C}_{8}-\mathrm{H}$ of 

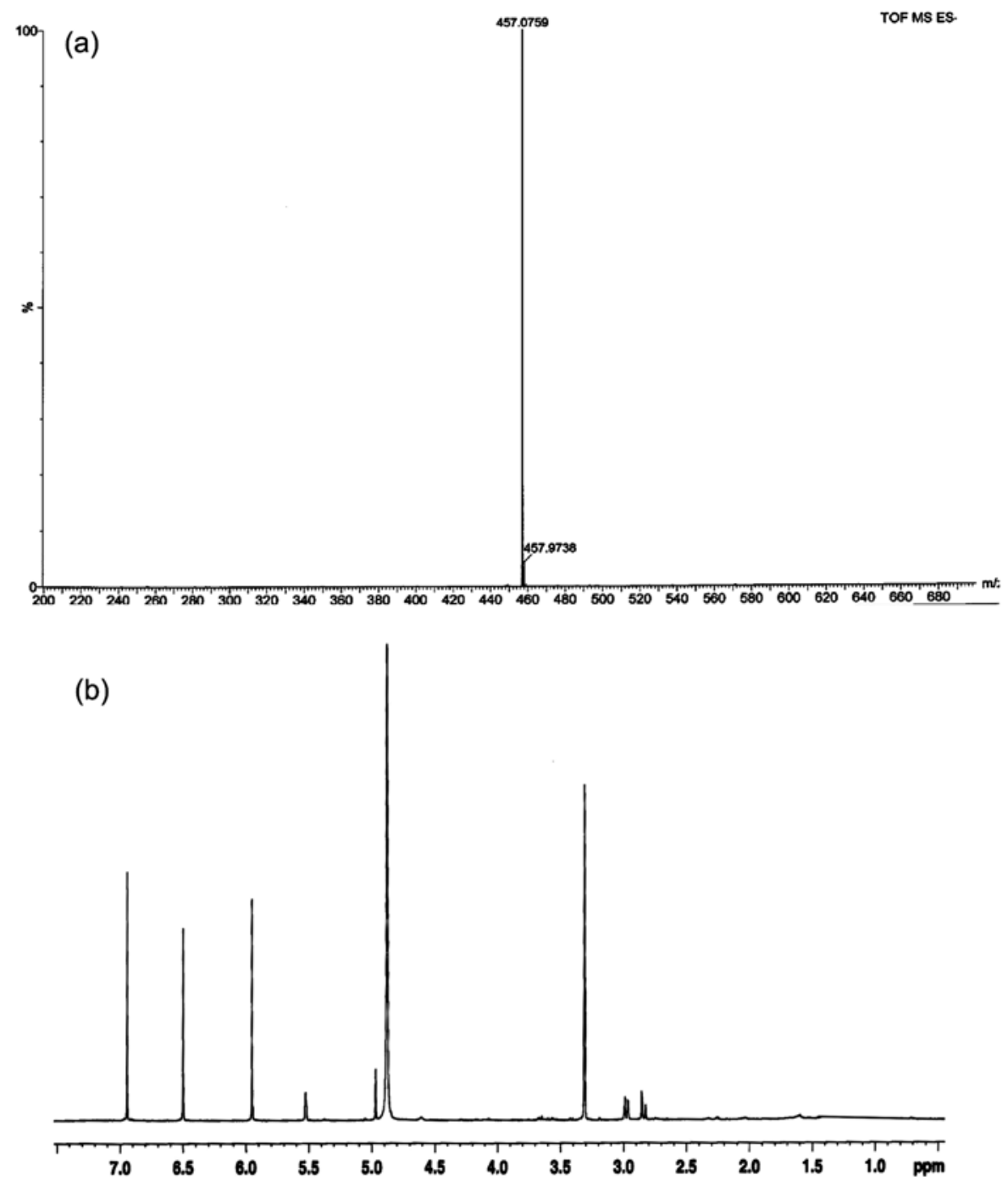

Fig. 1 (A) High resolution ESI - Mass spectrum of the compound EGCG in negative mode. (B) ${ }^{1} \mathrm{H}$ NMR spectrum $(600 \mathrm{MHz})$ of EGCG in $\mathrm{CD}_{3} \mathrm{OD}$.

the compound. The two proton singlet at $\delta 6.50 \mathrm{ppm}$ was assigned to $\mathrm{C}_{2^{\prime}}-\mathrm{H}$ and $\mathrm{C}_{6^{\prime}}-\mathrm{H}$ of the B-ring system. The down field signal at $\delta 6.95 \mathrm{ppm}(2 \mathrm{H}, \mathrm{s})$ was assigned to $\mathrm{C}_{2^{n}}-\mathrm{H}$ and $\mathrm{C}_{6^{n}}-\mathrm{H}$ of the galloyl moiety. Finally the compound was identified as (-) EGCG (Fig. 2) by comparison of its rotation value as also of spectral data with those of authentic sample (Valcic et al., 1999).

Again the CD spectra of EGCG showed peaks at $\lambda_{\text {ext }} 280(\Delta \in-1.8), 238(\Delta \in+1.41), 231(\Delta \in-4.33)$ and $214(\Delta \epsilon+22.1) \mathrm{nm}$. The CD spectrum was very similar to that of $(3 R, 3 R)$ flavan-3-ols indicating the $(2 R, 3 R)$ configuration of $(-)$ epigallocatechin 3gallate with $P$ helicity. Incidentally the $C D$ spectrum of EGCG was not reported earlier.

Antidiarrhoeal activity of EGCG by in vitro screening A total of $30 \mathrm{~V}$. cholerae strains were tested in vitro, of which $V$. cholerae 10, 522 and 976 were inhibited at $10 \mu \mathrm{g} / \mathrm{ml}$. Again $V$. cholerae 69, 71, 83, 214, 978, 1021, 1315, 1347, 1348, 569B and ATCC 14033 got inhibited at a concentration of $25 \mu \mathrm{g} / \mathrm{ml}$ while the 
<smiles>O=C(O[C@H]1Cc2c(O)cc(O)cc2O[C@@H]1c1cc(O)c(O)c(O)c1)c1cc(O)c(O)c(O)c1</smiles>

$(-)$ - Epigallocatechin 3 gallate

Fig. 2. Structure of EGCG.

Table 1. In vitro activity of EGCG on a number of strains of $V$. cholerae

\begin{tabular}{|c|c|c|c|c|c|c|c|}
\hline \multirow{2}{*}{ V. cholerae } & \multicolumn{7}{|c|}{ No. of strains inhibited by EGCG $(\mu \mathrm{g} / \mathrm{ml})$} \\
\hline & Control & 5 & 10 & 25 & 50 & 100 & 200 \\
\hline 10 & + & + & - & - & - & - & - \\
\hline DN16 & + & + & + & + & - & - & - \\
\hline DN26 & + & + & + & + & - & - & - \\
\hline 30 & + & + & + & + & - & - & - \\
\hline 42 & + & + & + & + & - & - & - \\
\hline 56 & + & + & + & + & - & - & - \\
\hline 58 & + & + & + & + & - & - & - \\
\hline 69 & + & + & + & - & - & - & - \\
\hline 71 & + & + & + & - & - & - & - \\
\hline 83 & + & + & + & - & - & - & - \\
\hline 113 & + & + & + & + & - & - & - \\
\hline 117 & + & + & + & + & - & - & - \\
\hline 154 & + & + & + & + & + & - & - \\
\hline 214 & + & + & + & - & - & - & - \\
\hline 522 & + & + & - & - & - & - & - \\
\hline 557 & + & + & + & + & + & - & - \\
\hline 564 & + & + & + & + & - & - & - \\
\hline 575 & + & + & + & + & + & - & - \\
\hline 593 & + & + & + & + & - & - & - \\
\hline 967 & + & + & + & + & + & - & - \\
\hline 972 & + & + & + & + & - & - & - \\
\hline 976 & + & + & - & - & - & - & - \\
\hline 978 & + & + & + & - & - & - & - \\
\hline 1021 & + & + & + & - & - & - & - \\
\hline 1315 & + & + & + & - & - & - & - \\
\hline 1347 & + & + & + & - & - & - & - \\
\hline 1348 & + & + & + & - & - & - & - \\
\hline $569 B$ & + & + & + & - & - & - & - \\
\hline ATCC 14033 & + & + & + & - & - & - & - \\
\hline ATCC 14035 & + & + & + & + & - & - & - \\
\hline
\end{tabular}

strains like $V$. cholerae DN 16, DN 26, 30, 42, 56, 58, 113, 117, 564, 593, 972 and ATCC 14035 were inhibited at $50 \mu \mathrm{g} / \mathrm{ml}$ concentration of the compound. Only four strains namely $V$. cholerae $154,557,575$ and 967 were inhibited at $100 \mu \mathrm{g} / \mathrm{ml}$ concentration (Table 1).

\section{Bacteriostatic action of EGCG}

The MIC of EGCG was found to be $25 \mu \mathrm{g} / \mathrm{ml}$ for $V$. cholerae 569B. At the logarithmic growth phase of the culture, when the CFU count of the strain was $3.0 \times 10^{8}, 50 \mu \mathrm{g} / \mathrm{ml}$ (double the MIC) of EGCG was added to the culture. Subsequently, the CFU of the culture was determined. For $V$. cholerae 569B, the CFU were $3.7 \times 10^{9}$ at $0 \mathrm{~h}, 1.1 \times 10^{8}$ after $2 \mathrm{~h}, 1.3 \times 10^{6}$ at the $4^{\text {th }} \mathrm{h}, 2.2 \times 10^{4}$ at the $6^{\text {th }} \mathrm{h}, 2.3 \times 10^{3}$ at the $8^{\text {th }} \mathrm{h}$ and $2.3 \times 10^{3}$ at the $18^{\text {th }} \mathrm{h}$. It was clear from the experiment that the isolated compound EGCG was bacteriostatic against $V$. cholerae 569B. This has been shown graphically in (Fig. 3).

\section{In vivo tests}

In vivo activity was determined by administering rabbit virulent strain $V$. cholerae $569 \mathrm{~B}$ into the ileal loops of a male New Zealand white rabbit. Of the four loops prepared, the negative control loop, showed absence of bacterial growth hence the CFU count was ' 0 '. Again the positive control loop, as it

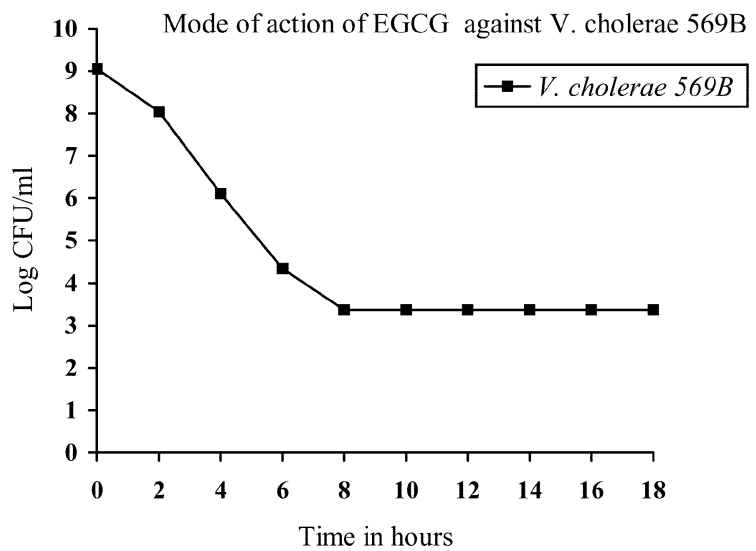

Fig. 3. Mode of action of EGCG against $V$. cholerae 569B. 
contains the highest volume of bacterial culture, exhibited the presence of highest number of $\mathrm{CFU} / \mathrm{ml}$ which was found to be $1.13 \times 10^{9}$. In comparison to this the other two loops containing two different concentrations of the said compound EGCG (500 $\mu \mathrm{g} / \mathrm{ml}$ and $1,000 \mu \mathrm{g} / \mathrm{ml}$ respectively) showed reduced number of $\mathrm{CFU} / \mathrm{ml}$. The loop having lower concentration of drug showed a CFU count of 2.15 $\times 10^{7}$ and the loop containing higher concentration of drug exhibited a CFU count of $4.1 \times 10^{5}$. Thus it is evident that the loop having $1,000 \mu \mathrm{g} / \mathrm{ml}$ of EGCG showed most significant reduction in the bacterial count.

\section{DISCUSSION}

It has been found from the above experiment that one of the major catechins EGCG isolated from the decaffeinated powder of green tea, was able to show good antidiarrhoeal activity when tested against a number of $V$. cholerae strains in vitro. Isolated catechin was found to be more sensitive against 7 strains including 569B while it showed less activity against others (Table 1). Hence it is evident from the study that the strains inhibited at $10 \mu \mathrm{g} / \mathrm{ml}$ are said to be highly sensitive towards the compound. Strains which got inhibited at 25 $\mu \mathrm{g} / \mathrm{ml}$ and $50 \mu \mathrm{g} / \mathrm{ml}$ can also be considered as highly sensitive and rest of the strains inhibited at $100 \mu \mathrm{g} / \mathrm{ml}$ can be regarded as moderately sensitive. Moreover the compound was totally non-toxic to animals even at very high concentrations.

In the in vivo experiment performed in rabbit ileum with the help of $V$. cholerae $569 \mathrm{~B}$ to establish the antidiarrhoeal activity of the compound EGCG, the protection rendered by the compound was found to be significant. Since green tea has long been used as a much preferred drink worldwide without any report of toxicity, the compound isolated from the crude green tea extract can therefore be recommended as a potent antidiarrhoeal agent which can be developed in future as a more acceptable herbal drug without any toxic side effect. Again this finding has corroborated our earlier studies (Dastidar et al., 2001; Kawase et al., 2001; Shirataki et al., 2001; Mazumder et al., 2003; Bandyopadhyay et al., 2005) to establish medicinal plants and phytochemicals as the outstanding alternative. Furthermore, synergistic combination with other phytochemicals may improve the therapeutic index.

\section{ACKNOWLEDGEMENTS}

Authors wish to thank Herbicure Healthcare BioHerbal Research Foundation, Kolkata, for the financial help and collaborative research work.

\section{REFERENCES}

Amarowicz R, Shahidi F. (2003) Presence of two forms of methylated (-)- epigalocatechin-3-gallate in green tea. Nahrung 47, 21-23.

Balentine DA, Wiseman SA, Bowens LC. (1997) The Chemistry of tea flavonoids. Crit. Rev. Food Sci. Nutr. 37, 693-704

Bandyopadhyay D, Chatterjee TK, Dasgupta A, Jeyaseeli L, Dastidar SG. (2005) In vitro and in vivo antimicrobial action of tea: The commonest beverage of Asia. Biol. Pharm. Bull. 28, 2125-2127.

Barrow GI, Feltham RKA. (1993) Cowan and Steel's Manual for the identification of medical bacteria. pp. 50-164, Cambridge University Press, Cambridge, U.K.

Bettolo MGB, Nicoletti N, Patamia M. (1981) Plant screening by chemical and chromatographic procedures under field conditions. J. Chromat. 213, 113-127.

Chakraborty S, Mukhopadhyay AK, Bhadra RK. (2000) Virulence genes in environmental strains of Vibrio cholera. Environ. Microbiol. 66, 4022-4028.

Dastidar SG, Mahapatra SK, Ganguly K, Chakrabarty AN. (2001) Antimicrobial activity of prenylflavanones. In vivo 15, 519-523.

De SN, Chatterje DN. (1953) An experimental study of the mechanism of action of Vibrio cholerae on the intestinal mucous membrane. J. Pathol. Bacteriol. 66, 559-562.

Gorbach SL, Banwell JG, Jacobs B. (1970) Intestinal microflora in Asiatic cholera. II. The small bowel. J. Infect. Dis. 121, 38-45. 
Graham HN. (1992) Green tea composition, consumption and polyphenol chemistry. Prev. Med. 21, 334-350.

Gupta S, Ahmad N, Mohan RR, Husain MM, Mukhtar H. (1999) Prostate cancer chemoprevention by green tea: in vitro and in vivo inhibition of testosteronemediated induction of ornithine decarboxylase. Cancer Res. 59, 2115-2120.

Hara KY, Ogura A, Noguchi Y, Terao K, Kumagai S. (1997) Effect of hemorrhagic toxin produced by Clostridium sporogenes on rabbit ligated intestinal loop. Microb. Pathog. 22, 31-38.

Hasegawa R, Chujo T, Sai-Kato K, Umemura T, Tanimura A, Kurokawa Y. (1995) Preventive effects of green tea against liver oxidative DNA damage and hepatotoxicity in rats treated with 2-nitropropane. Food Chem. Toxicol. 33, 961-970.

Hirose M, Hoshiya T, Akagi K, Futakuchi M, Ito N. (1994) Inhibition of mammary gland carcinogenesis by green tea catechins and other naturally occurring antioxidants in female Sprague-Dawley rats pretreated with 7,12-dimethylbenz[alpha]anthracene. Cancer Lett. 83, 149-156.

Hiroshi O, Daisuke M, Masami M. (2002) Identification in traditional herbal medications and confirmation by synthesis of factors that inhibit cholera toxininduced fluid accumulation. Proc. Natl. Acad. Sci. U.S.A. 99, 3042-3046.

Kawase M, Varu B, Shah A, Motohashi N, Tani S, Saito S, Debnath S, Mahapatra S, Dastidar SG, Chakrabarty AN. (2001) Antimicrobial activity of new coumarin derivatives. Arzneimittelforschung 51, 67-71.

Mazumder R, Dastidar SG, Basu SP, Mazumder A, Kumar S. (2003) Emergence of Mesua ferrea Linn. leaf extract as a potent bactericide. Ancient Sci. Life 22, 160-165.

Muramatsu K, Fukuyo M, Hara Y. (1986) Effect of green tea catechins on plasma cholesterol level in cholesterol-fed rats. J. Nutr. Sci. Vitaminol. 32, 613-622. Nagamori MH, Okai Y. (2001) Identification and antioxidant activity of several pigments from the residual green tea (Camellia sinensis) after hot water extraction. J. UOEH 23, 335-344.

National Committee for Clinical Laboratory Standards. "Methods for Dilution in Antimicrobial Susceptibility Tests". (1993) Approved Standard M2-A5. NCCLS, Villanova, PA.

Peker H, Srinivasan MP, Smith JM, Benj Mc Coy. (1992) Caffeine Extraction Rates from Coffee Beans with Supercritical Carbon Dioxide. AIChE J. 38, 761769.

Saldana MDA, Mohamed RS, Mazzfera P. (2000) Supercritical Carbon dioxide extraction of methylxanthines from mate tea leaves. Braz. J. Chem. Eng. 17.

Shirataki Y, Motohashi N, Tani S, Sakagami H, Satoh K, Nakashima H, Mahapatra SK, Ganguly K, Dastidar SG, Chakrabarty AN. (2001) In vitro biological activity of prenylflavanones. Anticancer Res. 21, 275280.

Suzuki H, Ishigaki A, Hara Y. (1998) Long-term effect of a trace amount of tea catechins with perilla oil on the plasma lipids in mice. Int. J. Vitam. Nutr. Res. 68, 272-274.

ValcicS, Muders A, Jacobsen NE, Liebler DC, Timmermann BN. (1999) Antioxidant chemistry of green tea catechins. Identiication of products of the reaction of (-) Epigalo Catechin Gallate with peroxi radicals. Chem. Res. Toxicol. 12, 382 -386.

Wang S, Noh SK, Koo SI. (2001) Green tea catechins inhibit porcine pancreatic phospholipase $\mathrm{A}_{2}\left(\mathrm{pPLA}_{2}\right)$ activity in vitro. FASEB J. 15, LB305 (abs.).

Yang TT, Koo MW. (1997) Hypocholesterolemic effects of Chinese tea. Pharmacol. Res. 35, 505-512.

Yang TT, Koo MW. (2000) Chinese green tea lowers cholesterol level through an increase in fecal lipid excretion. Life Sci. 66, 411-423. 